\title{
Biomass and dry matter production in planted forests and an adjacent secondary forest in the grassland area of Sakaerat, northeastern Thailand
}

\author{
K. Kamo, T. Vacharangrura, S. Tiyanon, C. Viriyabuncha, S. Nimpila, B. Duangsrisen, R.
} Thaingam, and M. Sakai

In TROPICS Volume 17, number 3 209-224 (published May 2008), The Y axis label of Figure 8 was given incorrectly.

On page 220, the Figure 8 was corrected as follow.

The authors apologize for this error.

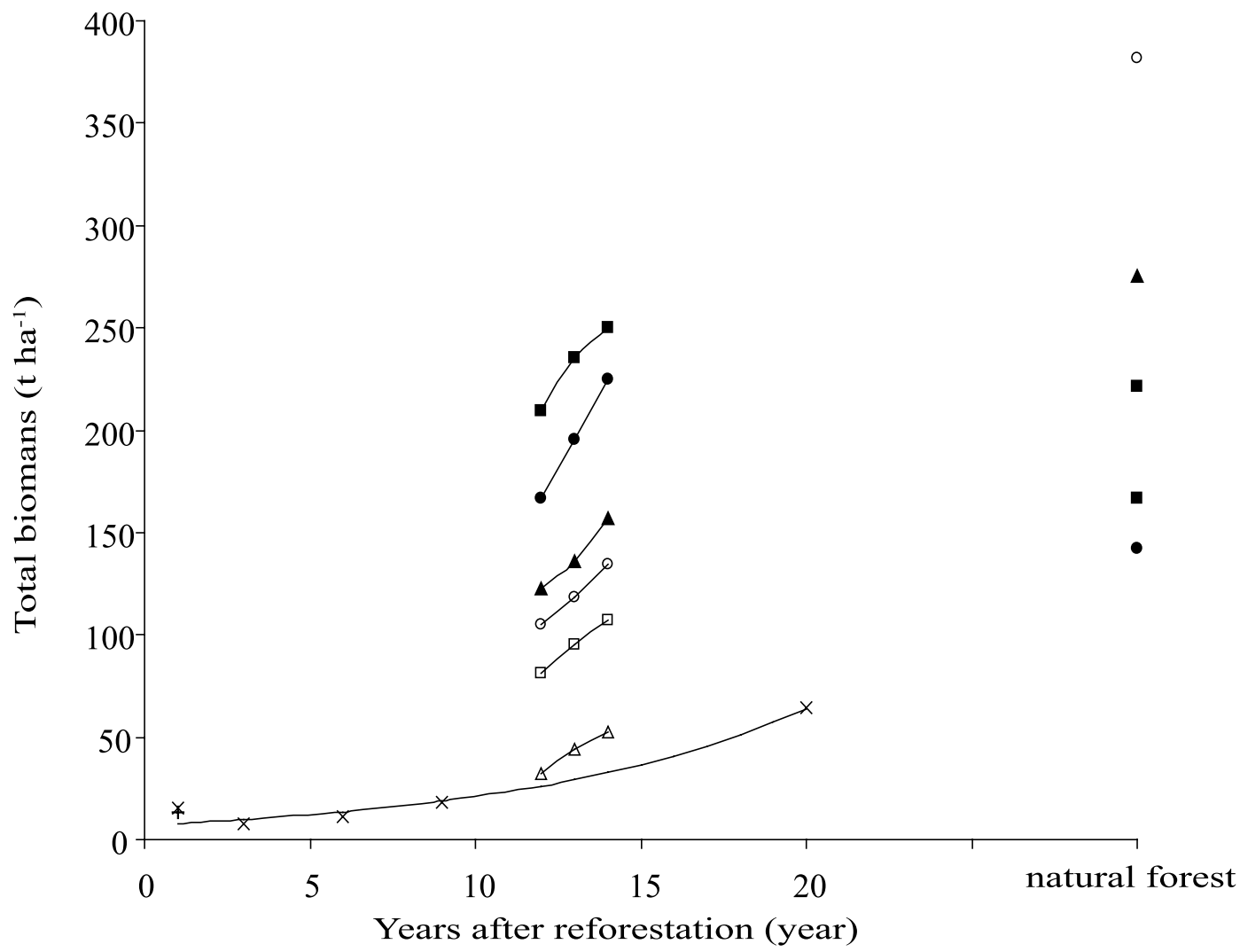

\footnotetext{
+ I. cylindrica grassland

$\rightarrow-A$. mangium stand

- - D. cochinchinensis stand

$\triangle P$. macrocarpus stand

- Secondary dry evergreen forest

- Dry evergreen forest in Sakaerat area (3)
}

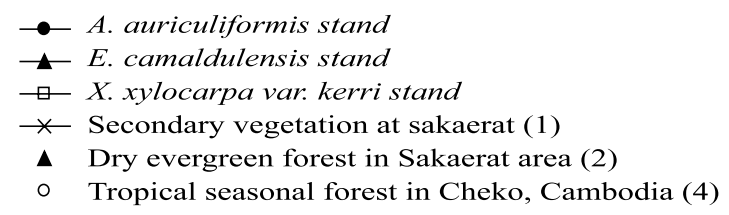

Fig. 8. Total aboveground and belowground biomass accumulations in the plantations after reforestation, secondary vegetation regenerated in abandoned fields, secondary forest and natural forests. The biomass of secondary vegetation was obtained from Drew et al. (1978), who measured the biomass of stands that were $1,3,6,9$, and 20 years old after cultivation and burning had ceased at Sakaerat. I. cylindrica grassland was assumed to be a 1-year old stand in the diagram. The biomass accumulation of this secondary vegetation was regressed using a logistic equation. For reference, the estimates of biomass in undisturbed dry evergreen forests at Sakaerat (Ogino et al., 1967, Sabhasri et al., 1968) and a tropical seasonal forest in Cambodia (Hozumi et al., 1969) are shown at the right end of the diagram. The total biomass was estimated by assuming the T/R ratio to be 5.3 (Hozumi et al., 1969) for secondary and primary forest stands and 0.66 (Kiyono, 2001) for I. cylindrica grassland. 